\title{
Enhancement of Adhesion between EPDM and Polyester Fabric by Using Natural Rubber Modified by Maleic Anhydride
}

\author{
A. A. El-Wakil \\ Polymer Metrology and Technology, National Institute of Standards, Tersa Street, Harm, P.O. Box 136, Giza 12211, Egypt \\ Correspondence should be addressed to A. A. El-Wakil, abdelaziz_elwakil@yahoo.com
}

Received 26 February 2011; Revised 30 April 2011; Accepted 20 May 2011

Academic Editor: Hj Din Rozman

Copyright (๑ 2011 A. A. El-Wakil. This is an open access article distributed under the Creative Commons Attribution License, which permits unrestricted use, distribution, and reproduction in any medium, provided the original work is properly cited.

This study presents a new method for improving adhesion between ethylene propylene diene monomer (EPDM) rubber and polyester fabric. In this work, natural rubber was modified by maleic anhydride in order to improve the adhesion force between ethylene propylene diene monomer rubber and polyester fabric. The effect of thermal aging and ionizing radiation on the stability of the rubber mix as well as on the peel strength of the rubber-coated fabric was investigated. It was observed that the natural rubber modified by maleic anhydride improved the peel strength of the EPDM rubber-coated polyester fabric.

\section{Introduction}

Modification of the surface by introducing polar groups such as peroxide functionalities has been a main route to improve adhesion of polyolefins, and the synthesis of block copolymers consisting of a polyolefin-like part and a polar part is another alternative approach to improve the adhesion of polyolefins. The idea of these two methods is to utilize the interaction between the polar groups and the target material to improve adhesion. Based on the same idea, the surface adhesion of substrates can be improved effectively by surface graft copolymerization since the surface graft chains could be designed to have considerable polarity $[1,2]$.

The modification of rubber is one alternative method to prepare a product that has some improved properties than that of the unmodified rubber. One of the most important rubbers is natural rubber (NR) because of its attractive range of properties which allows it to compete with synthetic rubbers. The NR backbone, cis-1,4-polyisoprene, facilitates certain types of chemical modification to yield a wide range of modified NR. The mechanical properties of the adhesive interface layer are critical in the design and application of adhesive structural components in general engineering applications [3].

Ethylene propylene diene monomer (EPDM) rubber is one of the fastest growing synthetic rubbers on the market today. It can be widely used in many fields due to its saturated hydrocarbon backbone with the presence of double bonds in side chains [4-10]. Several workers have reported that the rubber to polyester fabric adhesion was poor due to reduction in the number of hydrogen bonds or due to a lack of reactive hydrogen in the polyester molecules as well as its hydrophobic nature. For this reason, several attempts were made to improve the ethylene propylene diene monomer (EPDM) rubber/polyester adhesion by the selection of suitable additives in the rubber mix. The adhesion promoter used consists of hexamethylene tetramine, resorcinol, and hydrated silica (HRH system). The resorcinol was also replaced by o-aminophenol or $\mathrm{m}$-phenylene-diamine. In order to increase the resistance of the rubber mix towards senvironmental conditions and to increase its resistance towards thermal aging, and ionizing radiation different commercial antioxidants were used. Also newly prepared antioxidant was used to studying its effect on the adhesion between EPDM rubber and polyester fabric as well as its effect on aging and resistance to ionizing radiation $[11,12]$. The aim of this article is study the effect of natural rubber modified by maleic anhydride on the adhesion between ethylene propylene diene monomer and polyester fabric.

\section{Experimental}

2.1. Materials. Natural rubber, NR, poly cis-isoprene, was supplied by Amco International company (Maharashtra, 
India). EPDM rubber was supplied by HK Chuangsheng Rubber \& Plastic Co. (Guangdong, China). The untreated polyester fabric was supplied by the Egyptian Company for yarn and fine fabric (Kafr el-Dawwar, Egypt). It has the following features:

(1) fabric width: 38 in,

(2) weight in $\mathrm{m}^{2}: 119 \mathrm{~g} / \mathrm{m}^{2}$,

(3) number of yarns in warp: 68 yarn/in,

(4) number of yarn in weft: 68 yarn/in.

2.2. Natural Rubber Modified by Using Maleic Anhydride. Natural rubber modified by using maleic anhydride was prepared by using Ultra Violet radiation technique and specified by IR spectroscopy technique [13]. A previous study used the ultrasonic and differential scanning calorimeter techniques to study the effect of natural rubber modified by MA on the compatibility of NR-NBR blends. The results obtained showed that the addition of NR-g-MA to the blend showed improvement of compatibility in certain concentration ranges and deterioration of compatibility in other ranges.

2.3. Rubber Mix Formulation. The mixes examined in this study were based on ethylene propylene diene monomer (EPDM); the basic formulation is given in Table 1.

Zinc oxide and stearic acid were used in the mixes as an inorganic accelerator activator and organic acid accelerator activator, respectively. Naphthenic oil was used as processing oil in the mixes. Semireinforcing furnace (SRF) was used as carbon black in the mixes at one concentration $30 \mathrm{phr}$ (part per hundred). Sulfur was used as a vulcanizing agent in all mixes. The accelerators used were mercaptobenzthiazole (MBT) and tetramethylthiuram disulphide (TMTD). Nphenyl- $\mathrm{N}^{\prime}$-isopropyl-p-phenylenediamine (IPPD) was used as commercial antioxidant.

Mastication and mixing were carried out using a watercooled two-roll mill $\left(300 * 150 \mathrm{~mm}^{2}\right)$ operating at friction ratio $1.25: 1$. Rheometer tests at $152^{\circ} \mathrm{C}$ indicated that $90 \%$ crosslinking occurs at the corresponding cure time for each EPDM mix. All samples were cured at this temperature and the specific cure time.

2.4. Preparation of EPDM Coated Polyester Fabric. The unvulcanized EPDM mixes were cut into small pieces and immersed in toluene in order to swell and disperse to form the rubber dough. The rubber mix to solvent ratio was $1: 1$. The rubber dough was allowed to swell for $48 \mathrm{~h}$ in a closed vessel and then mixed thoroughly by manual stirring to ensure dough homogeneity.

A spreading machine was used to spread the rubber dough over the polyester fabric. The thin rubber layer ( $0.1 \mathrm{~mm}$ thick) formed at the surface of the fabric was dusted with talc powder and folded forming a fabric-rubberrubber fabric composite of thickness $\sim 0.6 \mathrm{~mm}$.

The rubber-coated fabric was wrapped with a cotton cloth and rolled around a metal drum, then blanketed again with cotton to prevent warping during cure. The drum was
TABLE 1: EPDM mix formulation containing Vulkasil s, Vulcacil h, resorcinol, and NR modified by MA.

\begin{tabular}{lcccc}
\hline $\begin{array}{l}\text { Mix name } \rightarrow \\
\text { Ingredients }^{\text {a }} \downarrow\end{array}$ & A1 & A2 & A3 & A4 \\
\hline EPDM & 100 & 100 & 100 & 100 \\
ZnO & 5 & 5 & 5 & 5 \\
Stearic acid & 2 & 2 & 2 & 2 \\
S & 1.5 & 1.5 & 1.5 & 1.5 \\
MBT $^{\text {b }}$ & 0.75 & 0.75 & 0.75 & 0.75 \\
TMTD $^{\text {c }}$ & 1.00 & 1.00 & 1.00 & 1.00 \\
SRF $_{\text {Processing oil }}$ & 30 & 30 & 30 & 30 \\
IPPD $^{\text {d }}$ & 5 & 5 & 5 & 5 \\
Vulkacil s $^{\mathrm{e}}$ & 1.5 & 1.5 & 1.5 & 1.5 \\
Vulcacil h$^{\mathrm{f}}$ & - & 5 & - & 5 \\
Resorcinol & - & 5 & - & 5 \\
NR modified by & - & 5 & - & 5 \\
MA & - & - & 5 & 5 \\
\hline
\end{tabular}

\footnotetext{
${ }^{a}$ Parts by weight.

${ }^{b}$ Mercaptobenzthiazole.

'Tetramethylthiuram disulfide.

${ }^{\mathrm{d}} \mathrm{N}$-phenyl- $\mathrm{N}^{\prime}$-isopropyl-p-phenylenediamine.

${ }^{\mathrm{e}}$ Hydrated silica.

${ }^{\mathrm{f}}$ Hexamethylene tetramine.
}

transferred to an air-circulating oven adjusted at $152^{\circ} \mathrm{C}$ for the optimum cure time of the mixes which was estimated by the MDR 2000 rheometer [14].

2.5. Irradiation Procedure. To study the effect of radiation on the adhesion between the EPDM rubber and the polyester fabric, the samples were exposed to Cobalt 60 at a dose rate of $6.5 \mathrm{~K}$ gray $/ \mathrm{h}$. The samples were exposed to doses ranging between 0.25 and $1.00 \mathrm{M}$ rad (irad $=0.01$ gray). The exposed samples were examined $24 \mathrm{~h}$ after irradiation to allow the sample to relax.

2.6. Adhesion Force Measurements. The ASTM D3330/ D3330M-99 method for adhesion strength of rubber to fabrics was employed using a 20-mm-wide test strip, long enough to permit separation over at least $100 \mathrm{~mm}$. The fabric and rubber were separated manually over a length of about $50 \mathrm{~mm}$, and the two ends were placed in the grips of a Zwick tensile testing machine. The grips were separated at a rate of $50 \pm 5 \mathrm{~mm} / \mathrm{min}$.

2.7. Thermal Aging. Aging was carried out according to ASTM D 573-a. Thermal oxidation of the vulcanized rubber polyester fabric assembly was carried out for different time durations in an air circulation oven at $90^{\circ} \mathrm{C}$.

\section{Results and Discussion}

3.1. Effect of Thermal Aging on Adhesion Force between EPDM and Polyester Fabric. As in accordance with the goals of this paper, the effect of aging through heating at certain humidity 


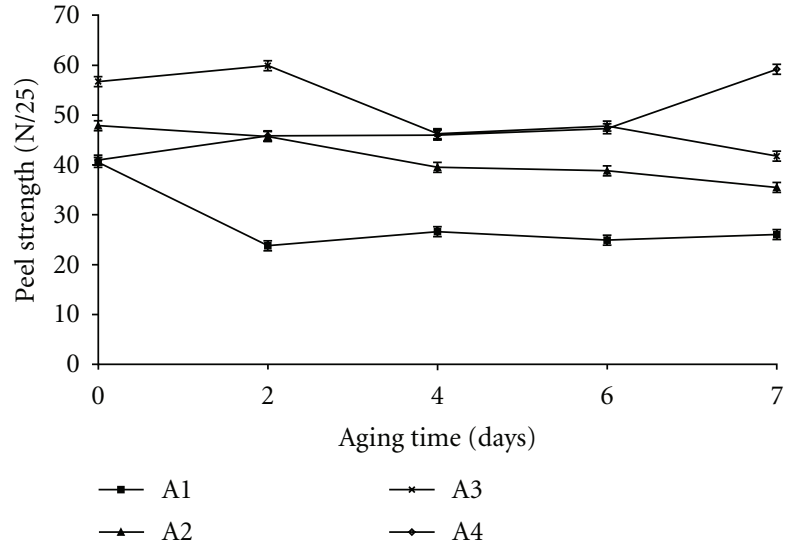

FIGURE 1: Effect of aging time on the adhesion strength between EPDM and polyester fabric.

exposure (55\%) was investigated. The investigation focused on two primary factors: time and aging conditions. Figure 1 shows the relation between peel strength between EPDM and polyethylene, and aging time. Aging conditions were the use of heat days: 2 days 4 days, 6 days and 7 days. The standard diviation of peel strength is $\pm 0.34 \mathrm{~N}$.

Relationship between $90^{\circ}$ peel adhesion and aging time is shown in Figure 1. For control mix, the value of peel adhesion significantly decreases with an increase of aging time at 2 days then it slightly decreases with increasing aging time up to 7 days, for EPDM mix that contains Vulkacil s, Vulcacil $h$, resorcinol, and EPDM mix that contains NR modified by MA. The values of the peel adhesion slightly decrease with increasing aging time from 0 day to 7 days. Figure 1 shows that the EPDM mix that contain NR modified by MA have better peel adhesion value than $\mathrm{A}_{2}$, and $\mathrm{A}_{1}$ mixes that, respectively. For EPDM mix that contains Vulkacil s, Vulcacil $h$, resorcinol, and NR modified by MA, the values of the peel strength increase with increasing aging time, because NR modified by MA increase the interfacial adhesion between EPDM and polyester fabric, and resulted in enhanced peel strength $[15,16]$. Natural rubber modified by maleic anhydride is chemically reactive and reacts with polyester fabric, and it has capability of imparting certain degree of miscibility. Therefore, natural rubber modified by maleic anhydride enhances the interfacial adhesion between EPDM and polyester [16].

\subsection{Effect of Radiation on Adhesion Force between EPDM and} Polyester Fabric. Figure 2 shows that the radiation dose was broken down into four increments: $0-\mathrm{M}$ rad, $0.25 \mathrm{M}$ rad, $0.5 \mathrm{M} \mathrm{rad}, 0.75 \mathrm{M} \mathrm{rad}$, and $1.00 \mathrm{M}$ rad. At the end of each radiation dose, peel strength testing was performed on the specimens. Figure 2 shows the dependence of peel strength of EPDM mixes and polyester fabric on the $\gamma$-radiation dose. It is clear that the EPDM mix, which containing Vulkacil s, Vulcacil h, resorcinol, and NR modified by MA, and EPDM mix taht contains NR modified by MA have higher peel strength than EPDM mix contains Vulkacil s, Vulcacil h, resorcinol and the control mix, respectively. Modification of

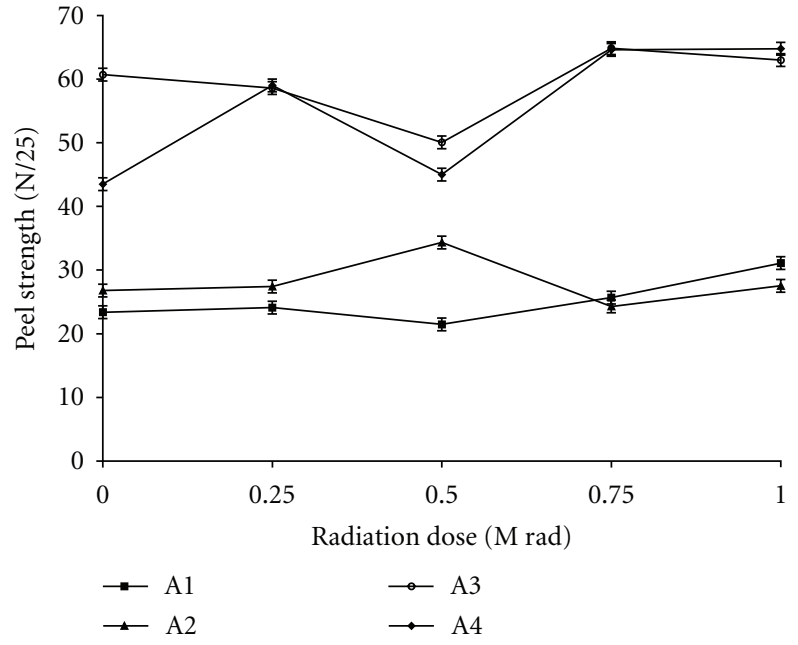

FIGURE 2: Effect of radiation on adhesion force between EPDM and polyester fabric.

polymer by introducing polar groups has been main route to improve adhesion of polyolefins. Modified polyolefins consist of a polyolefin-like part and a polar part [1]. Therefore, the natural rubber modified by maleic anhydride improved the adhesion between EPDM mix and polyester fabric. The natural rubber modified by maleic anhydride has good ability to penetrate and interweave through porous polyester fabric. When the adhesives sets, it anchors itself into the substrate [17-19].

In general, it can be observed from Figure 2 that natural rubber modified by maleic anhydride enhances adhesion between the EPDM and polyester fabric. Comparing the overall results shows that natural rubber modified by maleic anhydride enhances the adhesion for oven-vulcanized samples $[20,21]$.

Chemical modifications such as alkali, acetic anhydride, stearic acid, permanganate, maleic anhydride, silane and peroxides were given to the polymer and were found to be successful in improving the interfacial adhesion and compatibility between the fibre and matrix. It was found that the extent of improvement in adhesion and physical and chemical bonding between fibre and polymer matrix are the reasons for superior peel strength [18-20].

\section{Conclusions}

(1) The values of the peel strength of EPDM mix that contains Vulkacil s, Vulcacil h, resorcinol, and NR modified by MA increase with increasing aging time.

(2) The EPDM mix that contains NR modified by MA has higher peel strength than EPDM mix containing Vulkacil s, Vulcacil h, resorcinol, and the control mix respectively.

(3) It was observed that the natural rubber modified by maleic anhydride improved the adhesion between the EPDM rubber and the polyester fabric. 


\section{References}

[1] H. Wang, "Improving the adhesion of polyethylene by UV grafting," The Journal of Adhesion, vol. 82, no. 7, pp. 731-745, 2006.

[2] J. Lei, J. Gao, and L. Jiang, "Structure and adhesion properties of linear low-density polyethylene powders grafted with acrylic acid via ultraviolet light," Journal of Applied Polymer Science, vol. 100, no. 3, pp. 2549-2553, 2006.

[3] S. Kongparakul, P. Prasassarakich, and G. L. Rempel, "Catalytic hydrogenation of styrene-g-natural rubber (ST-g-NR) in the presence of $\mathrm{OsHCl}(\mathrm{CO})(\mathrm{O} 2)(\mathrm{PCy} 3) 2$," The European Polymer Journal, vol. 45, no. 8, pp. 2358-2373, 2009.

[4] M. Ehsani, H. Borsi, E. Gockenbach, J. Morshedian, and G. R. Bakhshandeh, "An investigation of dynamic mechanical, thermal and electrical properties of housing materials for outdoor polymeric insulators," The European Polymer Journal, vol. 40, no. 11, pp. 2495-2503, 2004.

[5] E. Meuleman, J. Willemsen, M. Mulder, and M. Strathmann, "EPDM as a selective membrane material in pervaporation," Journal of Membrane Science, vol. 188, no. 2, pp. 235-249, 2001.

[6] S. Jia, Z. Zhang, Z. Du, R. Teng, and Z. Wang, "A study of the dynamic flammability of radiation cross-linked flameretardant HDPE/EPDM/silicon-elastomer compound," Radiation Physics and Chemistry, vol. 66, no. 5, pp. 349-355, 2003.

[7] L. Yu, W. Wang, and W. Xiao, "The effect of decabromodiphenyl oxide and antimony trioxide on the flame retardation of ethylene-propylene-diene copolymer/polypropylene blends," Polymer Degradation and Stability, vol. 86, no. 1, pp. 69-73, 2004.

[8] I. Vieira, V. Severgnini, D. Mazera, M. Soldi, and E. Pinheiro, "Effects of maleated ethylene propylene diene rubber (EPDM) on the thermal stability of pure polyamides, and polyamide/EPDM and polyamide/poly(ethylene terephthalate) blends: kinetic parameters and reaction mechanism," Polymer Degradation and Stability, vol. 74, no. 1, pp. 151-157, 2001.

[9] D. Tillier, J. Meuldijk, and C. Koning, "Production of colloidally stable latices from low molecular weight ethylenepropylene-diene copolymers," Polymer, vol. 44, no. 26, pp. 7883-7890, 2003.

[10] P. Bhadane, M. Champagne, M. Huneault, F. Tofan, and B. Favis, "Continuity development in polymer blends of very low interfacial tension," Polymer, vol. 47, no. 8, pp. 2760-2771, 2006.

[11] T. Takeyama and J. Matsui, "Recent developments with tire cords and cord-to-rubber bonding," Rubber Chemistry and Technology, vol. 42, no. 1, p. 159, 1969.

[12] S. Lawandy, A. Younan, N. Yousef, N. Darwish, and A. Mounir, "Adhesion properties of butyl rubber-coated polyester fabric," Journal of Adhesion Science and Technology, vol. 11, no. 3, pp. 317-325, 1997.

[13] H. Afifi and A. A. El-Wakil, "Study of the effect of natural rubber-graft-maleic anhydride (NR-g-MA) on the compatibility of NR-NBR blends using the ultrasonic technique," Polymer-Plastics Technology and Engineering, vol. 47, no. 10, pp. 1032-1039, 2008.

[14] S. F. Halim, A. I. Abou-Kandil, A. Awad, and N. Darwish, "In situ grafting of maleic anhydride onto natural rubber to improve its adhesion to polyester fabric: mechanical and spectroscopic analyses," Journal of Adhesion Science and Technology, vol. 23, no. 1, pp. 71-83, 2009.
[15] S. Thomas and G. Groeninckx, "Reactive compatibilisation of heterogeneous ethylene propylene rubber (EPM)/nylon 6 blends by the addition of compatibiliser precursor EPM-gMA," Polymer, vol. 40, no. 21, pp. 5799-5819, 1999.

[16] M. Jacob, K. Varughese, and S. Thomas, "Mechanical properties of sisal/oil palm hybrid fiber reinforced natural rubber composites," Composites Science and Technology, vol. 64, no. 7-8, pp. 955-965, 2004.

[17] J. Deng, L. Wang, L. Liu, and W. Yang, "Developments and new applications of UV-induced surface graft polymerizations," Progress in Polymer Science, vol. 34, no. 2, pp. 156-193, 2009.

[18] H. Bruning and H. Borgholte, "Coating of untreated polypropylene with halogen free aqueous materials," Progress in Organic Coatings, vol. 40, no. 1-4, pp. 49-54, 2000.

[19] I. Kim, P. S. Kang, and C.-S. Ha, "Efficient graft-from functionalization of ethylene-propylene-diene rubber (EPDM) dissolved in hexane," Reactive and Functional Polymers, vol. 64, no. 3, pp. 151-156, 2005.

[20] M. A. L. Manchado, M. Arroyo, J. Biagiotti, and J. M. Kenny, "Enhancement of mechanical properties and interfacial adhesion of PP/EPDM/flax fiber composites using maleic anhydride as a compatibilizer," Journal of Applied Polymer Science, vol. 90, no. 8, pp. 2170-2178, 2003.

[21] D. M. Jia and X. I. Zhang, "Effect of MAH modified carbon black prepared by solid state grafting in situ on the adhesion between nylon 66 cords and natural rubber and dynamic mechanical properties of the vulcanizates," Rubber Chemistry and Technology, vol. 75, no. 4, pp. 669-681, 2002. 

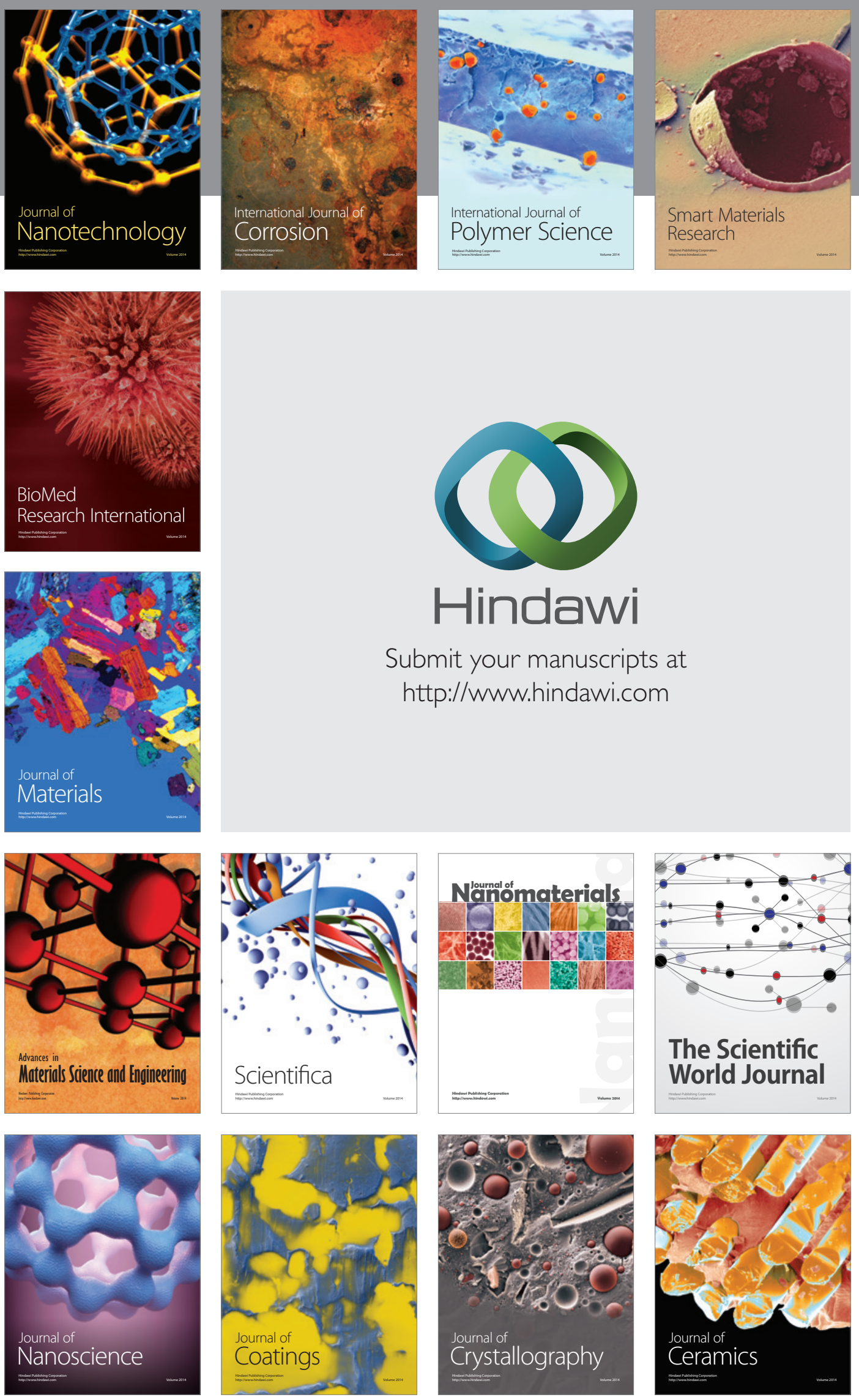

The Scientific World Journal

Submit your manuscripts at

http://www.hindawi.com

\section{World Journal}

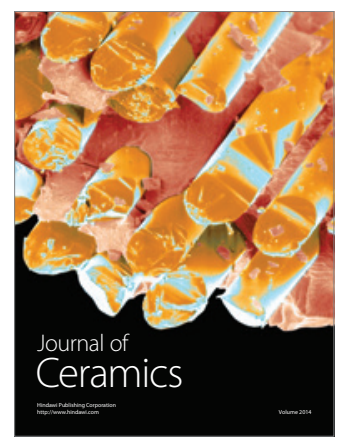

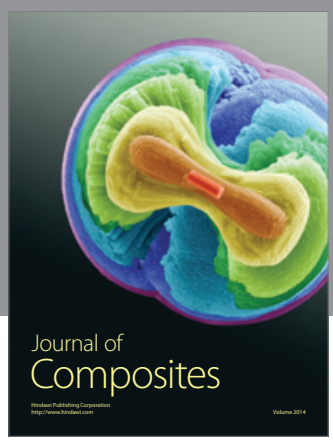
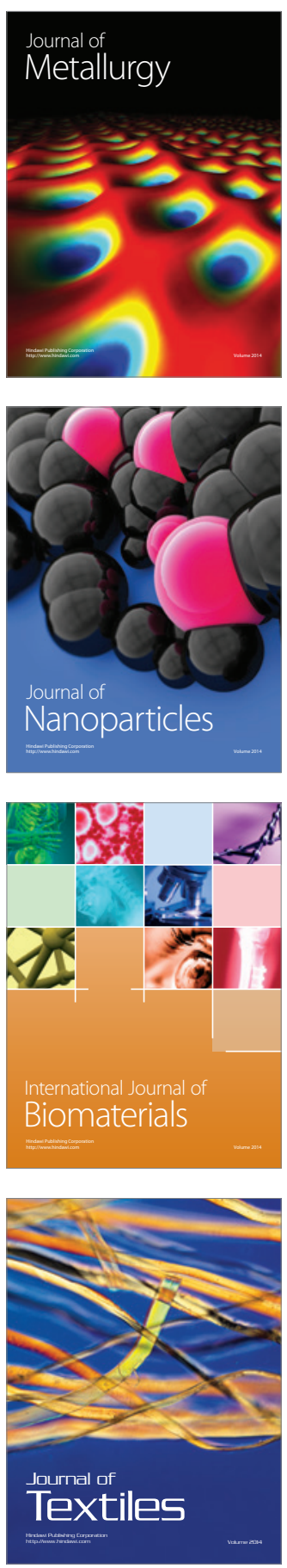